\title{
An introduction to the EULAR-OMERACT rheumatoid arthritis MRI reference image atlas
}

\author{
M Østergaard, J Edmonds, F McQueen, C Peterfy, M Lassere, B Ejbjerg, P Bird, P Emery, H Genant, \\ P Conaghan
}

Ann Rheum Dis 2005;64(Suppl I):i3-i7. doi: 10.1136/ard.2004.031773

This article gives a short overview of the development and characteristics of the OMERACT rheumatoid arthritis MRI scoring system (RAMRIS), followed by an introduction to the use of the EULAR-OMERACT rheumatoid arthritis MRI reference image atlas. With this atlas, MRIs of wrist and metacarpophalangeal joints of patients with rheumatoid arthritis can be scored for synovitis, bone oedema, and bone erosion, guided by standard reference images.

See end of article for authors' affiliations .....................

Correspondence to: Prof $M$ Østergaard, Copenhagen University Hospital at Hvidovre, Kettegaard alle 30, DK2650 Hvidovre, Denmark; mo@dadlnet.dk
S tructural joint damage, a major outcome in rheumatoid arthritis (RA), has traditionally been measured by scoring methods applied to radiological images. ${ }^{1}$ However, only the late signs of preceding disease activity can be visualised by radiography. Magnetic resonance imaging (MRI) can detect RA erosive change with greater sensitivity than conventional radiography, particularly in early disease..$^{2-4}$ In addition, MRI allows direct visualisation and assessment of synovitis, the primary lesion in $\mathrm{RA}$, and of bone oedema, a finding unique to MRI and a probable forerunner of bone erosions. ${ }^{56}$ Given these advantages, MRI has a major potential as an outcome measure in RA clinical trials but standardised, validated, and feasible assessment systems are needed.

\section{THE OMERACT AND EULAR MRI IN RA WORKING GROUPS} in Rheumatology Clinical Trials (OMERACT) MRI in RA working group has aimed to develop MRI scoring systems to assess RA inflammation (activity) and damage, which would satisfy the elements of the OMERACT filter (truth, discrimination, and feasibility). ${ }^{7}$ The group's work has mainly focused on semiquantitative assessments of RA wrist and metacarpophalangeal (MCP) joints. The wrist and MCP joints were prioritised because of their frequent involvement in RA (including early RA), the fact that these joints are included in traditional clinical and radiological scoring systems in RA, and the large amount of MRI data on these joints. ${ }^{8-12}$ MRI definitions of important RA joint pathologies and a core set of basic MRI sequences to be used for imaging of the RA joint have been suggested by the group, in order to increase comparability between future studies. ${ }^{13}$ Furthermore, based on a series of studies performed by an European League Against Rheumatism (EULAR) MRI in RA working group, ${ }^{14}{ }^{15}$ and particularly the
Since 1998, an international Outcome Measures
OMERACT group, ${ }^{16-18}$ an RA MRI scoring system (OMERACT 2002 RAMRIS) for evaluation of inflammatory and destructive changes in RA hands and wrists was presented at OMERACT 6 in Brisbane, Australia, in April 2002. OMERACT 6 participants endorsed the OMERACT 2002 RAMRIS as a standard comparator for new/ alternative MRI methods for RA assessment and encouraged its further testing in longitudinal studies. ${ }^{19}$ Recent data have documented good intraobserver and interobserver agreements among trained, calibrated readers ${ }^{2021}$ and indicate an improved sensitivity to change for erosive joint damage by using this MRI score as compared with radiography. ${ }^{62}$ The evidence for the validity of MRI for assessment of joint inflammation and destruction in RA is reviewed elsewhere. $^{23} 24$

Our group felt that the performance and generalisability of RAMRIS scoring could be improved by availability of a set of standard reference images (atlas), as synovitis scores in particular may be difficult for new readers to conceptualise. Therefore, it was decided to focus the group's efforts on developing the reference image atlas presented in this supplement for use as a guide to scoring of RA joint pathology, based on the OMERACT 2002 RAMRIS method.

\section{SCORING USING THE EULAR-OMERACT RA MRI REFERENCE IMAGE ATLAS}

The OMERACT MRI in RA definitions of important joint pathologies and scoring system ${ }^{13}$ are summarised in table 1. Examples of score sheets, which can be used when scoring MCP and wrist joints, are provided in fig 1 .

The methodology of the development of the atlas is described in detail in the following paper by Bird et al. ${ }^{25} \mathrm{Next}$, the atlas itself is presented $^{2627}$ :

- a complete series of all grades of synovitis in the MCP joints and in each of the wrist joint areas (distal radioulnar joint, radiocarpal joint and intercarpal-carpometacarpal joints); and

- a selection of grades of bone erosions and bone oedema in the two MCP joint bones (metacarpal head and phalangeal base) and five selected wrist joint bones (distal radius, scaphoid, lunate, capitate, metacarpal base).

Abbreviations: EULAR, European League Against Rheumatism; MCP, metacarpophalangeal; MRI, magnetic resonance imaging; OMERACT, Outcome Measures in Rheumatology Clinical Trials; RA, rheumatoid arthritis 


\section{Score sheet for the OMERACT RAMRIS using the EULAR-OMERACT RA MRI reference image atlas MCP JOINTS}

MRI ID: Scorer's name:

Centre where MRI was performed:

Image set (e.g. baseline or follow-up):

Sequences scored:

Scoring of synovitis

\begin{tabular}{|c|c|c|c|c|}
\hline \multirow{2}{*}{} & \multicolumn{4}{|c|}{ MCP-joints } \\
\cline { 2 - 5 } & 2 & 3 & 4 & 5 \\
\hline Synovitis (0-3) & & & & \\
\hline
\end{tabular}

Scoring of bone erosion and bone oedema

Bone erosion is scored $0-10$, according to the proportion (in increments of $10 \%$ ) of bone involved:

$0: 0 \%, 1: 1-10 \%, 2: 11-20 \%, \ldots \ldots \ldots ., 10: 91-100 \%$

Bone oedema is scored 0-3, according to the proportion (in increments of $33 \%$ ) of bone involved:

$0: 0 \%, 1: 1-33 \%, 2: 34-66 \%, 3: 67-100 \%$

Score from the articular surface (or its best estimated position if absent) to a depth of 1 $\mathrm{cm}$.

\begin{tabular}{|cc|c|c|c|c|}
\hline \multirow{2}{*}{} & \multicolumn{4}{|c|}{ MCP joints } \\
\cline { 3 - 6 } & 2 & 3 & 4 & 5 \\
\hline $\begin{array}{c}\text { Bone } \\
\text { erosion } \\
0-10\end{array}$ & Proximal & & & & \\
\hline $\begin{array}{c}\text { Bone } \\
\text { oedema } \\
0-3\end{array}$ & Distal & & & & \\
\cline { 2 - 6 } & Proximal & & & & \\
\hline
\end{tabular}




\section{Score sheet for the OMERACT RAMRIS}

using the EULAR-OMERACT RA MRI reference image atlas

WRIST JOINTS

MRI ID:

Scorer's name:

Centre where MRI was performed:

Image set (e.g. baseline or follow-up):

Sequences scored:

\section{Scoring of synovitis}

Synovitis (0-3)

\section{Scoring of bone erosion and bone oedema}

Bone erosion is scored $0-10$, according to the proportion (in increments of $10 \%$ ) of bone involved: $0: 0 \%, 1: 1-10 \%, 2: 11-20 \%, \ldots \ldots \ldots ., 10: 91-100 \%$

Bone oedema is scored 0-3, according to the proportion (in increments of 33\%) of bone involved: $0: 0 \%, 1: 1-33 \%, 2: 34-66 \%, 3: 67-100 \%$

For carpal bones, score the whole bone. For long bones, score from the articular surface (or its best estimated position if absent) to a depth of $1 \mathrm{~cm}$.

\begin{tabular}{|l|l|l|l|l|l|}
\hline & \multicolumn{5}{|c|}{ Base of metacarpal } \\
Bone erosion (0-10) & $\mathbf{1}$ & $\mathbf{2}$ & $\mathbf{3}$ & $\mathbf{4}$ & $\mathbf{5}$ \\
\cline { 2 - 6 } & & & & & \\
\hline Bone oedema (0-3) & & & & & \\
\hline
\end{tabular}

\begin{tabular}{|l|l|l|l|l|} 
& Trapezium & Trapezoid & Capitate & Hamate \\
\cline { 2 - 5 } Bone erosion (0-10) & & & & \\
\hline Bone oedema (0-3) & & & & \\
\hline
\end{tabular}

\begin{tabular}{|l|l|l|l|l|}
\hline & Scaphoid & Lunate & Triquetrum & Pisiform \\
\cline { 2 - 5 } Bone erosion (0-10) & & & & \\
\hline Bone oedema (0-3) & & & & \\
\hline
\end{tabular}

\begin{tabular}{|l|l|l|}
\hline & Distal radius & Distal ulna \\
\cline { 2 - 3 } Bone erosion (0-10) & & \\
\hline Bone oedema (0-3) & & \\
\hline
\end{tabular}

Figure 1 Examples of score sheets that can be used for scoring (A) metacarpophalangeal and (B) wrist joints using the OMERACT 2002 rheumatoid arthritis magnetic resonance imaging scoring system (RAMRIS). The layout of the score sheet can be modified-for example, according to the features and joints that are to be examined in a specific patient material. 
Table 1 OMERACT MRI in RA group recommendations of a core set of basic MRI sequences, MRI definitions of important RA joint pathologies, and an RA MRI scoring system (OMERACT 2002 RAMRIS). ${ }^{13}$

A. Core set of basic MRI sequences

It is suggested that future MRI studies that intend to assess inflammatory as well as destructive changes in RA joints should at least include the following:

- Imaging in two planes* with T1 weighted images before and after intravenous gadolinium contrast†

- A T2 weighted fat saturated sequence or, if the latter is not available, a STIR (short tau inversion recovery) sequence

${ }^{*}$ Can be acquired by obtaining a two dimensional sequence in two planes, or a three dimensional sequence with isometrical voxels in one plane allowing reconstruction in other planes.

tIntravenous gadolinium injection is probably not essential if only destructive changes (bone erosions) are considered important.

\section{B. Definitions of important RA joint pathologies}

- Synovitis: an area in the synovial compartment that shows above normal post-gadolinium enhancement* of a thickness greater than the width of the normal synovium

- MRI bone erosion: a sharply marginated bone lesion, with correct juxta-articular localisation and typical signal characteristicst, which is visible in two planes with a cortical break seen in at least one planef

- MRI bone oedema: A lesion $\uparrow$ within the trabecular bone, with ill defined margins and signal characteristics consistent with increased water content§

* Enhancement is judged by comparison of $\mathrm{T} 1$ weighted images obtained before and after intravenous gadolinium contrast. †An T1 weighted images this is loss of normal low signal intensity of cortical bone and loss of normal high signal intensity of trabecular bone. Quick post-gadolinium enhancement suggests presence of active, hypervascularised pannus tissue in the erosion. ‡ Other focal bone lesions, including metastases must obviously be considered but are generally distinguishable with associated imaging and clinical findings.

- May occur alone or surrounding an erosion or other bone abnormalities.

$\S$ High signal intensity on weighted fat saturated and STIR images, and low signal intensity on T1 weighted images.

\section{Scoring system (OMERACT 2002 RAMRIS)}

- Synovitis: is assessed in three wrist regions (the distal radioulnar joint; the radiocarpal joint; the intercarpal and carpometacarpal joints) and in each MCP joint. The first carpometacarpal joint and the first MCP joint are not scored. The scale is $0-3$. Score 0 is normal, and $1-3$ (mild, moderate, severe) are by thirds of the presumed maximum volume of enhancing tissue in the synovial compartment

- Bone erosions: each bone (wrists: carpal bones, distal radius, distal ulna, metacarpal bases; MCP joints: metacarpal heads, phalangeal bases) is scored separately. The scale is $0-10$, based on the proportion of eroded bone compared to the "assessed bone volume", judged on all available images - 0: no erosion; 1: 1-10\% of bone eroded; $2 ; 11-20 \%$, etc. For long bones, the "assessed bone volume" is from the articular surface (or its best estimated position if absent) to a depth of $1 \mathrm{~cm}$, and in carpal bones it is the whole bone

- Bone oedema: each bone is scored separately (as for erosions). The scale is 0-3 based on the proportion of bone with oedema, as follows-0: no oedema; 1: 1-33\% of bone oedematous; 2 : $34-66 \%$ of bone oedematous; $3: 67-100 \%$

The final paper by McQueen et al describes the common and important pitfalls involved in scoring MR images of RA wrist and MCP joints. ${ }^{28}$

To use the atlas adequately, the reader is obviously required to have a detailed understanding of the relevant joint anatomy, the RA disease process, the MRI appearance of RA joints using common sequences, and the main pitfalls when assessing them. Furthermore, the "requirements" of the OMERACT RAMRIS ${ }^{13}$ (see table 1) and the content of the atlas $^{25-28}$ should be known. Calibration with a trained reader is recommended. Given these requirements, scoring of hard copy or digital MR image sets of wrist and MCP joints can be performed guided by the standard reference images of MCP joints ${ }^{26}$ and wrist joints ${ }^{27}$ provided in this supplement.

We suggest that when using this atlas, the reader compares the relevant images with the images in this atlas. Synovitis is scored from 0 to 3 in each area to be evaluated (see table 1). The MRI set to be assessed should be compared with the axial precontrast and postcontrast $\mathrm{Tl}$ weighted reference images and the joint assigned the score of the best possible match.
This is similar to the Larsen method for scoring radiographs. In the atlas, examples of both the "low" and the "high" end of the spectrum of the individual grade are provided to illustrate the range of the grade (see Bird et $a^{25}$ for details).

Bone erosion is graded by percentage volume $(0-10$, by $10 \%$ volume increments) of the assessed bone as described in the OMERACT RAMRIS (see table 1). All coronal slices covering the bone must be assessed to estimate the percentage of the total volume occupied by the erosion. Even though only a subset of bones are illustrated in the atlas, we recommend that all bones in the wrist and MCP joints should be scored. The reference images in the atlas can be used for guidance and calibration.

Bone oedema is graded by percentage volume $(0-3$, by $33 \%$ volume increments) of the assessed bone as described in the OMERACT RAMRIS (table 1). As for erosion, all slices covering the bone need to be taken into account. It should be emphasised that oedema, in case erosion and oedema are concurrently present, is scored as a proportion of the estimated original bone volume, not of the remaining bone. 
All bones of the wrist and second to fifth MCP joints should be scored, not just the subset illustrated. The atlas reference images can be used for guidance and calibration.

Sum scores of synovitis, erosion, and oedema can be calculated by summation of individual joint scores, as a total sum or separately in the evaluated wrist and second to fifth MCP joints, respectively. For synovitis, the possible range of sum scores of unilateral second to fifth MCP joints, wrist joint, and both are $0-12,0-9$, and $0-21$, respectively. The corresponding values for bone erosion are 0-80, 0-150, and $0-230$ and for bone oedema $0-24,0-45$, and $0-69$, respectively.

In conclusion, we hope we have provided a user friendly tool for teaching new readers and improving calibration for all who use MRI outcomes in RA clinical trials.

\section{ACKNOWLEDGEMENT}

The European League Against Rheumatism (EULAR) is acknowledged for financial support of the publication of this atlas.

\section{Authors' affiliations}

M Østergaard, Departments of Rheumatology, Copenhagen University Hospitals at Herlev and Hvidovre, Copenhagen, Denmark

J Edmonds, Department of Rheumatology, St George Hospital,

University of NSW, Sydney, Australia

F McQueen, Department of Molecular Medicine and Pathology, Faculty of Medicine and Health Sciences, University of Auckland, Auckland, New Zealand

C Peterfy, Synarc Inc, San Francisco, CA, USA

M Lassere, Department of Rheumatology, St George Hospital, University of NSW, Sydney, Australia

B Ejbjerg, Departments of Rheumatology, Radiology and MRI, Copenhagen University Hospital at Hvidovre, Copenhagen, Denmark

P Bird, Department of Rheumatology, St George Hospital, University of NSW, Sydney, Australia

P Emery, Academic Unit of Musculoskeletal Disease, University of Leeds, Leeds, UK

H Genant, Department of Radiology, University of California at San Francisco, San Francisco, CA, USA

P Conaghan, Academic Unit of Musculoskeletal Disease, University of Leeds, Leeds, UK

\section{REFERENCES}

1 van der Heijde DMFM. Plain X-rays in rheumatoid arthritis: overview of scoring methods, their reliability and applicability. Bailleres Clin Rheumatol 1996; 10:435-53.

2 McQueen FM, Stewart N, Crabbe J, Robinson E, Yeoman S, Tan PL, et al. Magnetic resonance imaging of the wrist in early rheumatoid arthritis reveals a high prevalence of erosion at four months after symptom onset. Ann Rheum Dis 1998;57:350-6.

3 Backhaus M, Kamradt T, Sandrock D, Loreck D, Fritz J, Wolf KJ, et al. Arthritis of the finger joints. A comprehensive approach comparing conventional radiography, scintigraphy, ultrasound, and contrast-enhanced magnetic resonance imaging. Arthritis Rheum 1999;42:1232-45.

4 Lindegaard H, Vallø J, Hørslev-Petersen K, Junker P, Østergaard M. Low field dedicated magnetic resonance imaging in untreated rheumatoid arthritis of recent onset. Ann Rheum Dis 2001;60:770-6.

5 McQueen FM, Stewart N, Crabbe J, Robinson E, Yeoman S, Tan PL, et al. Magnetic resonance imaging of the wrist in early rheumatoid arthritis reveals progression of erosions despite clinical improvement. Ann Rheum Dis 1999:58:156-63

6 Conaghan PG, O'Connor P, McGonagle D, Astin P, Wakefield RJ, Gibbon WW, et al. Elucidation of the relationship between synovitis and bone damage: a randomized magnetic resonance imaging study of individual joints in patients with early rheumatoid arthritis. Arthritis Rheum 2003;48:64-71.
7 Boers M, Brooks P, Strand CV, Tugwell P. The OMERACT filter for Outcome Measures in Rheumatology. J Rheumatol 1998;25:198-9.

8 Fleming A, Benn RT, Corbett M, Wood PH. Early rheumatoid disease. II. Patterns of joint involvement. Ann Rheum Dis 1976;35:361-4.

9 Larsen A, Dale K, Eek M. Radiographic evaluation of rheumatoid arthritis and related conditions by standard reference films. Acta Radiol Diagn 1977; 18:481-91.

10 Sharp JT, Young DY, Bluhm GB, Brook A, Brower AC, Corbett M, et al. How many joints in the hands and wrists should be included in a score of radiologic abnormalities used to assess rheumatoid arthritis? Arthritis Rheum 1985;28:1326-35.

11 Prevoo ML, van't Hof MA, Kuper HH, van Leeuwen MA, van de Putte LB, van Riel PL. Modified disease activity scores that include twenty-eight-joint counts. Development and validation in a prospective longitudinal study of patients with rheumatoid arthritis. Arthritis Rheum 1995;38:44-8.

12 Felson DT, Anderson JJ, Boers M, Bombardier C, Chernoff M, Fried B, et al. The American College of Rheumatology preliminary core set of disease activity measures for rheumatoid arthritis clinical trials. Arthritis Rheum 1993:36:729-40.

13 Østergaard M, Peterfy C, Conaghan P, McQueen F, Bird P, Ejbjerg B, et al. OMERACT Rheumatoid Arthritis Magnetic Resonance Imaging Studies. Core set of MRI acquisitions, joint pathology definitions, and the OMERACT RA-MRI scoring system. J Rheumatol 2003;30:1385-6.

14 O'Connor P, Østergaard M, Klarlund M, Peterfy C, Astin P, van der Heijde D, et al. Longitudinal evaluation of MRI scoring in rheumatoid arthritis - an international multicenter study of interreader agreement [abstract]. Arthritis Rheum 2001:44:315.

15 Østergaard M, Conaghan P, O'Connor P, Ejbjerg B, Szkudlarek M, Peterfy C, et al. Reducing costs, duration and invasiveness of magnetic resonance imaging in rheumatoid arthritis by omitting intravenous gadolinium injection-does it affect assessments of synovitis, bone erosions and bone edema? [abstract]. Ann Rheum Dis 2003;62(suppl I):67.

16 Østergaard M, Klarlund M, Lassere M, Conaghan P, Peterfy C, McQueen F, et al. Interreader agreement in the assessment of magnetic resonance images of rheumatoid arthritis wrist and finger joints - an international multicenter study. J Rheumatol 2001;28:1143-50.

17 Conaghan $\mathrm{P}$, Lassere $\mathrm{M}$, Østergaard $\mathrm{M}$, Peterfy $\mathrm{C}, \mathrm{Mc}$ Queen $\mathrm{F}, \mathrm{O}^{\prime}$ Connor $\mathrm{P}$, et al. OMERACT Rheumatoid Arthritis Magnetic Resonance Imaging Studies. Exercise 4: an international multicenter longitudinal study using the RA-MRI Score. J Rheumatol 2003;30:1376-9.

18 Lassere M, McQueen F, Østergaard M, Conaghan P, Shnier R, Peterfy C, et al. OMERACT Rheumatoid Arthritis Magnetic Resonance Imaging Studies. Exercise 3: an international multicenter reliability study using the RA-MRI Score. J Rheumatol 2003;30:1366-75.

19 McQueen F, Lassere M, Edmonds J, Conaghan P, Peterfy C, Bird P, et al. OMERACT Rheumatoid Arthritis Magnetic Resonance Imaging Studies. Summary of OMERACT 6 MR Imaging Module. J Rheumatol 2003;30:1387-92

20 Bird P, Lassere M, Shnier R, Edmonds J. Computerized measurement of magnetic resonance imaging erosion volumes in patients with rheumatoid arthritis: a comparison with existing magnetic resonance imaging scoring systems and standard clinical outcome measures. Arthritis Rheum 2003;48:614-24.

21 Haavardsholm EA, Kvan NP, Østergaard M, Ejbjerg B, Uhlig TA, Lilleas FF, et al. Reliability of the OMERACT Rheumatoid Arthritis MRI Score (RAMRIS) in a Multi-Reader Longitudinal Setting [abstract]. Arthritis Rheum 2004;50(suppl 9):S457-S458.

22 Ejbierg B, Vestergaard A, Jacobsen S, Thomsen HS, Østergaard M. The Sensitivity to Change for Destructive Joint Damage by the Sharp/Van Der Heijde X-Ray Scores and 2 Different MRI Approaches [abstract]. Arthritis Rheum 2004;50(suppl 9):S172.

23 Conaghan P, McQueen F, Peterfy C, Lassere M, Ejbjerg B, Bird P, et al. The evidence for MRI as an outcome measure in proof-of-concept rheumatoid arthritis studies. J Rheumatol 2005 (in press).

24 Østergaard M, Duer A, Døhn UM, et al. MRI of peripheral joints in rheumatic diseases. Best Pract Res Clin Rheumatol 2004;18:861-79.

25 Bird P, Conaghan P, Ejbjerg B, McQueen F, Lassere M, Peterfy C, et al. The development of the EULAR-OMERACT rheumatoid arthritis MRI reference image atlas. Ann Rheum Dis 2005:65(suppl I):i8-10.

26 Conaghan $\mathrm{P}$, Bird P, Ejbierg B, O'Connor P, McQueen F, Peterfy C, et al. The EULAR-OMERACT rheumatoid arthritis MRI reference image atlas: the metacarpophalangeal joints. Ann Rheum Dis 2005;65(suppl I):i1 1-21.

27 Ejbjerg B, McQueen F, Lassere M, Haavardsholm E, Conaghan P, $\mathrm{O}^{\prime}$ Connor $\mathrm{P}$, et al. The EULAR-OMERACT rheumatoid arthritis MRI reference image atlas: the wrist joint. Ann Rheum Dis 2005;65(suppl I):i23-47.

28 McQueen F, Østergaard M, Peterfy C, Lassere M, Ejbjerg B, Bird P, et al. Pitfalls in MRI scoring of rheumatoid arthritis wrist and metacarpophalangeal joints. Ann Rheum Dis 2005;65(suppl I):i48-55. 